\title{
Microscopic and macroscopic measurements of emphysema: relation to carbon monoxide gas transfer
}

\author{
A McLean, P M Warren, M Gillooly, W MacNee, D Lamb
}

\begin{abstract}
Background Studies of the relation between the severity of structural change in emphysema and physiological abnormality have been based on macroscopic assessments, which have not been truly quantitative or sensitive enough to detect early changes. With a highly reproducible method for measuring emphysema using histological sections and a semiautomatic image analysis system, this quantitative assessment of emphysema was compared with a semiquantitative macroscopic assessment of emphysema and measurements of carbon monoxide gas transfer.
\end{abstract}

Methods Microscopic and macroscopic measurements of emphysema on 44 thoracotomy specimens were compared; only two were from non-smokers. Airspace wall surface area per unit volume was measured microscopically with an automatic image analyser and expressed as both the mean airspace wall surface area per unit volume and the mean value of the five fields with the lowest values. Macroscopic emphysema was measured directly on a tracing of the midsagittal slice using a digitising tablet attached to a microcomputer and expressed as a percentage of the total area of lung. In cases with centriacinar emphysema the number of discrete lesions was counted.

Results The area of macroscopic emphysema ranged from 0 to $78 \%$ of the total area of lung examined, but most patients had less than $1 \%$ involvement so that the distribution was highly skewed. Both mean airspace wall surface area per unit volume and the mean of five fields with the lowest airspace wall surface area per unit volume were normally distributed, with mean airspace areas ranging from 8.8 to 25.4 $\mathrm{mm}^{2} / \mathrm{mm}^{3}$ (mean 18.1 $\mathrm{mm}^{2} / \mathrm{mm}^{3}$ ). In lobes with centriacinar emphysema the number of discrete lesions correlated with airspace wall surface area per unit volume and with preoperative carbon monoxide transfer factor (TLCO) per unit lung volume. However, other measurements of macroscopic emphysema did not correlate with loss of alveolar wall surface area, and there was considerable overlap between subjects with no or minimal macroscopic emphysema and those with more severe disease. TLCO correlated with both mean airspace wall surface area per unit volume and the mean of five fields with the lowest airspace wall surface area per unit volume but not with the severity of macroscopic emphysema.

Conclusion If emphysema is to be quantified it must be measured microscopically; macroscopic measurements do not, in general, reflect the microscopic loss of airspace wall.

Reid defined emphysema as "a condition of the lung characterised by an increase beyond normal in the size of airspaces distal to the terminal bronchiolus." Other definitions differ in whether the terms dilatation, destruction, or fibrosis are included. ${ }^{2-4}$ Although emphysema affects airflow, lung compliance, and gas transfer, its precise contribution to chronic obstructive airways disease is poorly understood, ${ }^{5}$ and in anatomical terms it is difficult to measure accurately as normal airspace size has yet to be established.

Centriacinar and panacinar emphysema are the two most common forms of the disease. They differ in their distribution within the acinus and to a lesser extent within the lung. ${ }^{6}$ Measurements and analysis of the two forms of emphysema have often been carried out separately, ${ }^{7-12}$ but they are now commonly regarded as part of a spectrum. ${ }^{12-19}$

Several qualitative methods have been devised to assess the severity of emphysema macroscopically. ${ }^{2021}$ After comparing several techniques Thurlbeck et al recommended the panel grading system because of its reproducibility, speed, and ease of use..$^{1022}$ This is a semiquantitative and subjective method in which whole lungs slices are graded from 0 to 100 against a panel of standards. However, standards do not represent a true arithmetic scale, the method does not measure the percentage of lung affected and centriacinar and panacinar emphysema are not scored separately. Alternatively, the role of macroscopic emphysema as a proportion of lung volume and airspace surface area can be quantified by counting points ${ }^{23}$ and by mean linear intercept techniques, ${ }^{24}$ or, as in our study, by measuring individual fields with a high degree of accuracy with computer based image analysers. 
Macroscopic assessment of emphysema is potentially insensitive to quite considerable losses of surface area. The average alveolar diameter is about $0.25 \mathrm{~mm}^{25}$ whereas the threshold value for detecting an emphysematous airspace macroscopically is $1 \mathrm{~mm} .^{23}$ This represents a 64 fold increase in airspace volume and, more importantly in terms of surface area available for gas exchange, a $75 \%$ reduction in surface area per unit volume (24 $\mathrm{mm}^{2} / \mathrm{mm}^{3}$ as opposed to $6 \mathrm{~mm}^{2} / \mathrm{mm}^{3}$ ).

In this study we used an image analyser to measure airspace wall surface area per unit lung volume-the surface area to volume relation of airspaces within the lung. Results obtained from this analysis were compared with an objective assessment of macroscopic emphysema. Macroscopic and microscopic measurements were compared with preoperative measurements of single breath carbon monoxide gas transfer.

\begin{abstract}
Materials and methods
Forty four lobes were obtained at thoracotomy from patients aged 46 to 74 years. All but two were smokers. In 29 cases the specimens were obtained by a lobectomy with a peripheral tumour confined to the segment of origin. The remaining 15 specimens were obtained at pneumonectomy: only the lobes free of tumour were used. Immediately after resection the lobes were infused with formalin intrabronchially at an applied pressure of $25 \mathrm{~cm} \mathrm{H}_{2} \mathrm{O}$ until fully distended. Once fixed the lungs were cut into $1 \mathrm{~cm}$ parasagittal slices.
\end{abstract}

\section{MACROSCOPIC ASSESSMENT}

The mid-sagittal lung slices were immersed in water and examined with a hand lens. Emphysematous areas were traced on to a clear polythene sheet placed over the slice, and their combined areas were measured on a digitising tablet linked to a microcomputer. Difficulty in outlining small centriacinar lesions-which never accounted for more than $1 \%$ or $2 \%$ of the total area-was overcome by measuring the diameter of each lesion with Vernier callipers and calculating their area assuming a circular configuration. Their summed cross sectional area was then added to the digitised figure. Macroscopic emphysema was expressed as the percentage area of the mid-sagittal slice occupied by airspaces of at least $1 \mathrm{~mm}$ in diameter. The number of centriacinar lesions was also recorded. To facilitate further analysis specimens were divided into four groupsnamely, those with no emphysema, those with pure centriacinar emphysema, those with pure

Table 1 Summary statistics of patients and details of lobes studied

\begin{tabular}{lllll}
\hline Variable & Mean & Range & $S D$ & $n$ \\
\hline Age (years) & 61 & $46-74$ & $6 \cdot 6$ & 44 \\
AWUV $\left(\mathrm{mm}^{2} / \mathrm{mm}^{3}\right.$ ) & $18 \cdot 12$ & $8 \cdot 78-25 \cdot 40$ & $3 \cdot 31$ & 44 \\
Mean & $12 \cdot 61$ & $1 \cdot 88-21 \cdot 26$ & $4 \cdot 50$ & 44 \\
LF5 & 8 & $0-79$ & $19 \cdot 3$ & 44 \\
Macroscopic emphysema (\% area) &
\end{tabular}

AWUV = airspace wall surface area per unit volume.

LF5 = mean of five lowest AWUV fields. panacinar emphysema, and those with both types of emphysema.

\section{MICROSCOPIC ASSESSMENT}

Six blocks $(2 \mathrm{~cm}$ by $2 \mathrm{~cm}$ ) were taken for microscopic assessment from each of the first two lateral subpleural slices with a transparent grid marked out in $2 \mathrm{~cm}$ squares and computer generated random numbers. Blocks were embedded in glycol methacrylate to give negligible processing artefact, ${ }^{26}$ and sections were cut at $3 \mu \mathrm{m}$ and stained with haematoxylin and eosin.

Airspace wall surface area per unit volume was measured with an IBAS2 image analyser (Kontron, Watford), a Bosch TYK 9A television camera with Chalnicon tube, and an Ortholux II light microscope with stabilised voltage illumination. Fields were chosen by randomly selecting one of the 12 stained sections and then locating a field from within that section with numbered coordinates from an England Finder (Graticules, Tonbridge, Kent) and computer generated random numbers. Fields containing structures such as bronchi, bronchioles, or accompanying vessels were rejected. The images of airspace walls were enhanced, and objects such as inflammatory cells were removed by applying a size filter or by interactive editing. Objects within the image such as small vessels whose inner aspects were not included in the calculation of airspace perimeter were filled interactively. Total airspace wall perimeter per unit area was then measured as mm per $\mathrm{mm}^{2}$ and airspace wall surface area per unit volume (AWUV) calculated by using the formula:

AWUV = Airspace wall perimeter per unit area $\times 4 / \pi^{27}$

A minimum of 20 fields in each case were analysed to obtain a stable running mean. The mean was deemed to be stable if it did not vary by more than $3 \%$ for five consecutive fields while showing no consistent upwards or downwards trend. To obtain a figure representing a portion of the lung with the least number of alveoli the mean for the lowest five airspace wall surface area per unit volume fields (LF5 AWUV) was calculated for each case.

Reproducibility was assessed by selecting six sections from the sample pool and measuring airspace wall surface area per unit volume in a single random field from each section. The England Finder coordinates of these fields were stored, and each field was relocated and measured repeatedly over 10 days without reference to previous results. The coefficient of variation $(\mathrm{CV})$ was calculated for the results from each section by using the formula:

$$
\mathrm{CV}=\text { standard deviation/mean }
$$

The coefficients of variation for all six sections were less than $1 \%$.

\section{CARBON MONOXIDE GAS TRANSFER}

Single breath carbon monoxide transfer factor was measured preoperatively in 36 of the 44 patients by Ogilvie's technique ${ }^{28}$ to obtain the transfer factor (TLCO) and transfer factor per unit lung volume (KCO). ${ }^{29}$ 
ANALYSIS

As the extent of macroscopic emphysema was not normally distributed within the sample the non-parametric Spearman correlation coefficient was used to relate macroscopic to microscopic measures of emphysema and to relate both to TLCO and KCO measurements with the statistical package for the social sciences.

\section{Results}

Summary statistics for all variables are given in table 1. Airspace surface area per unit volume (AWUV), expressed as both the mean value and the mean of the five lowest fields (LF5 AWUV), approximated to a normal distribution whereas macroscopic emphysema when expressed as a percentage of total lung area was not normally distributed (figure 1). In approximately half the lobes the area of macroscopic emphysema was $1 \%$ or less. Fifteen of the 44 lobes showed no macroscopic emphysema and 17 had pure centriacinar emphysema, six pure panacinar emphysema, five a mixture of centriacinar and panacinar emphysema, and one paraseptal emphysema alone.

\section{RELATION OF AWUV TO MACROSCOPIC} MEASUREMENT OF EMPHYSEMA AND TO TLCO AND Kco

AWUV did not correlate with body height and both mean and LF5 AWUV correlated poorly with the severity of macroscopic emphysema (figure 2). The overlap in AWUV values between cases with up to $1 \%$ and more than $1 \%$ macroscopic emphysema was extensive. Cases with up to $1 \%$ macroscopic emphysema had mean AWUV values ranging from 15.5 to $25.4 \mathrm{~mm}^{2} / \mathrm{mm}^{3}$, while in those with more severe emphysema the values ranged from 8.8 to $22.6 \mathrm{~mm}^{2} / \mathrm{mm}^{3}$. For LF5 AWUV the equivalent values were 9.9 to $21.3 \mathrm{~mm}^{2} / \mathrm{mm}^{3}$ and 1.9 to $18.7 \mathrm{~mm}^{2} / \mathrm{mm}^{3}$ respectively. Only two cases (figure 2)-both with extensive macroscopic emphysema-lay outside the range of mean AWUV values seen in lobes with up to $3 \%$ macroscopic emphysema. Mean and LF5 AWUV values showed a highly significant linear relation with both TLCO and KCO (figure 3 ) irrespective of the type of macroscopic emphysema present (table 2). The strongest correlations were between $\mathrm{KCO}$ and AWUV since both are expressed per unit lung volume

Figure 1 Frequency histogram of area of macroscopic emphysema expressed as percentage of total lung area in midsagittal slice. (table 2). The severity of macroscopic emphysema correlated poorly with Kco (figure 4) and there was considerable overlap in TLCo and $\mathrm{KCO}$ values between cases with up to $1 \%$ and more than $1 \%$ macroscopic emphysema (4.56 to 10.4 and 2.72 to $9.12 \mathrm{mmol} / \mathrm{min} / \mathrm{kPa}$ respectively for TLCO and 1.05 to 1.88 and 0.41 to $1.62 \mathrm{mmol} / \mathrm{min} / \mathrm{kPa} / 1$ respectively for $\mathrm{KCO}$ ).

\section{CENTRIACINAR EMPHYSEMA ONLY}

In all of the 17 lobes showing pure centriacinar emphysema less than $5 \%$ of the mid-sagittal slice was affected. Mean and LF5 AWUV in this group correlated significantly with both TLCO and $\mathrm{Kco}$ (table 2), the strongest correlation being between LF5 AWUV and KCO $(r=0.91, p<0.001)$. The area of macroscopic centriacinar emphysema (as a percentage of lung area) showed little correlation with AWUV, expressed as either mean or LF5 values, or with TLco or Kco. However, the number of discrete centriacinar lesions (mean 16.35 (SE 3.6), range 2-58) correlated with both mean $(r=0.60, p<0.005)$ and LF5 AWUV ( $r=0.73, p<0.001$ ) (figure 5). The number of centriacinar lesions also correlated with Kco (figure 6) but not TLCo.

\section{PANACINAR ONLY AND MIXED EMPHYSEMA}

In the six lobes with panacinar emphysema only the distribution of AWUV was not uniform. In some cases it approximated to a normal distribution while in others it was highly skewed. Five lobes showed a mixture of macroscopic panacinar and centriacinar emphysema. As panacinar emphysema was the predominant form of macroscopic emphysema by far, these five cases were analysed with the six cases of panacinar emphysema above. The percentage area of macroscopic emphysema bore little relation to either mean or LF5 AWUV. For example, when AWUV ranged from 14 to $16 \mathrm{~mm}^{2} / \mathrm{mm}^{3}$ the severity of macroscopic emphysema ranged from $3 \%$ to $51 \%$ by area (figure 2).

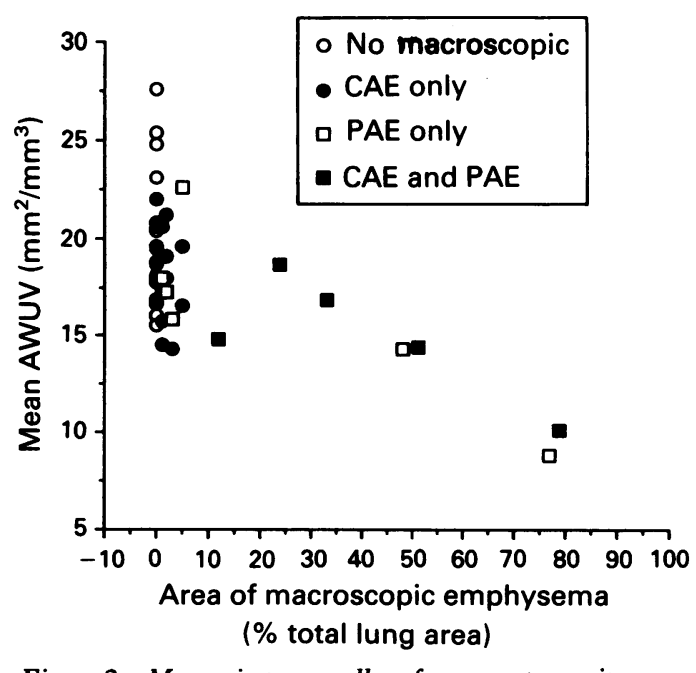

Figure 2 Mean airspace wall surface area per unit volume plotted against the area of macroscopic emphysema expressed as percentage of total lung area. The scatter of points shows that the relation between these variables is poor. $C A E=$ centriacinar emphysema; $P A E=$ panacinar emphysema; $A W U V=$ airspace wall surface area per unit volume. 
Table 2 Correlation coefficients ( $r$ ) for relation between AWUV and TLCO and KCO

\begin{tabular}{|c|c|c|c|c|c|c|}
\hline \multirow[b]{2}{*}{$A W U V$} & \multicolumn{2}{|c|}{$\begin{array}{l}\text { All cases } \\
(n=36)\end{array}$} & \multicolumn{2}{|c|}{$\begin{array}{l}\text { Centriacinar emphysema only } \\
(n=17)\end{array}$} & \multicolumn{2}{|c|}{$\begin{array}{l}\text { Any panacinar emphysema } \\
(n=11)\end{array}$} \\
\hline & TLCO & KCO & TLCO & Kco & TLCO & KCO \\
\hline Mean & $\begin{array}{c}0.61 \\
<0.001\end{array}$ & $\begin{array}{c}0.66 \\
<0.001\end{array}$ & $\begin{array}{l}0.81 \\
0.001\end{array}$ & $\begin{array}{l}0.77 \\
0.003\end{array}$ & $\begin{array}{l}0.54 \\
0.082\end{array}$ & $\begin{array}{l}0.73 \\
0.02\end{array}$ \\
\hline LF5 & $\begin{array}{c}0.73 \\
<0.001\end{array}$ & $\begin{array}{c}0.84 \\
<0.001\end{array}$ & $\begin{array}{l}0.84 \\
0.001\end{array}$ & $\begin{array}{l}0.91 \\
<0.001\end{array}$ & $\begin{array}{l}0.76 \\
0.015\end{array}$ & $\begin{array}{l}0.91 \\
0.001\end{array}$ \\
\hline
\end{tabular}

AWUV = airspace wall surface area per unit volume.

LF5 = mean of lowest five AWUV fields.

Figure 3 Relation

between single breath

transfer coefficient ( $\mathrm{KCO}$ )

and LF5 AWUV. These

two variables are expressed

in comparable units

$(r=0.84, p<0.001)$

$L F 5=$ mean of the five

lowest fields. Other

abbreviations as in figure 2.

Figure 4 Relation

between single breath $\mathrm{KCO}$ and area of macroscopic emphysema expressed as percentage of total lung area. Abbreviations as in figure 2 .

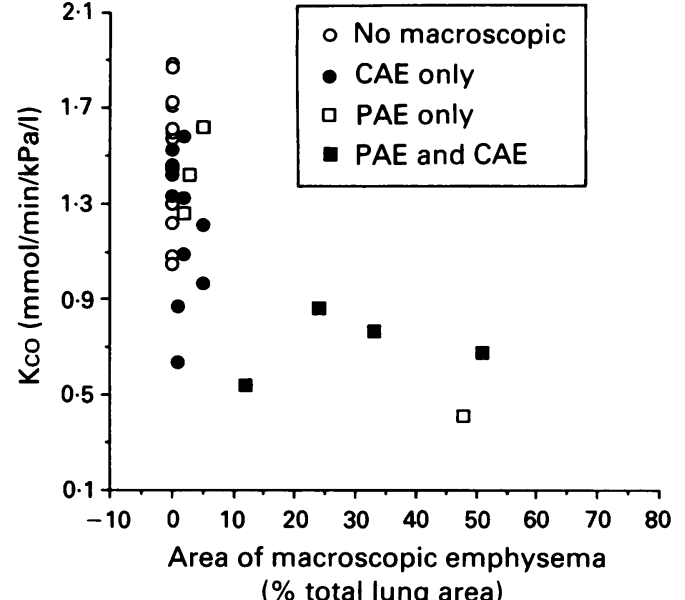

(\% total lung area)

Figure 5 Relation

between number of

centriacinar lesions and

LF5 AWUV $(r=-0.73$,

$p<0.001)$.

Abbreviations as in figure

2 and 3.
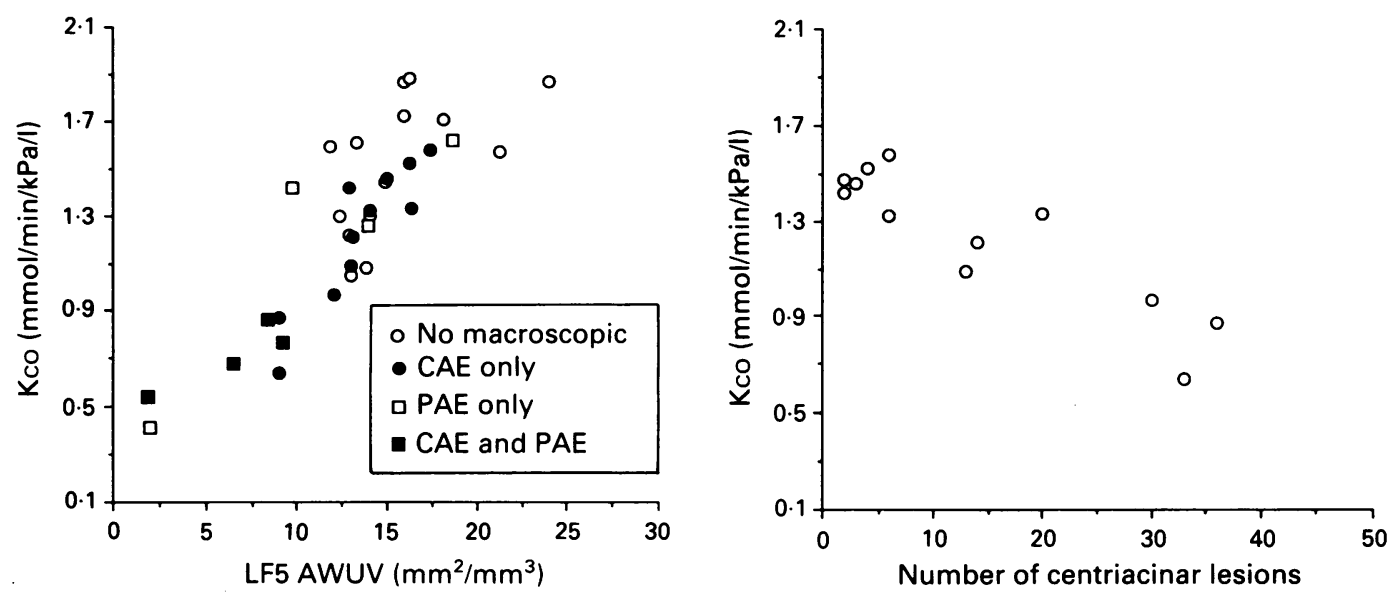

Figure 6 Relation between the number of centriacinar lesions and single breath transfer coefficient (KCO) $(r=-0.89, p<0.001)$.

Mean AWUV was correlated significantly with Kco and LF5 AWUV with both TLCo and Kco (table 2). The severity of macroscopic emphysema was poorly associated with both TLco and Kco.

\section{Discussion}

In this study airspace wall surface area per unit volume was measured by an image analysis technique. The linear intercept technique ${ }^{23}$ permits a more rapid assessment of airspace surface area, but image analysis has the advantage of giving highly reproducible individual field values, permitting the construction of histograms of airspace surface area for individual cases and comparison of the distribution of the airspace surface area within lobes.

Both the linear intercept and airspace wall surface area per unit volume are based on absolute measurement of airspace size and are therefore directly related and to a certain extent interchangeable. ${ }^{30}$ In this study airspace wall surface area per unit volume was independent of patient height, thus substantiating previous findings that the linear intercept ${ }^{31}$ and alveolar density $^{32}$ do not vary with height. Although total alveolar number and surface area are related to height, ${ }^{32}$ the almost threefold range of airspace wall surface area per unit volume values in this study cannot be explained on this basis and must be due, at least in part, to loss of airspace wall.

The measurement of airspace wall surface area per unit volume provides a continuous 
assessment of airspace size from normal to gross macroscopic abnormality. Macroscopic assessment, on the other hand, is discontinuous as it is based on an arbitrary threshold airspace size of $1 \mathrm{~mm}$ in diameter. The airspace wall surface area per unit volume can be remarkably low in lungs with minimal amounts of emphysema macroscopically, and there is considerable overlap between such cases and those with much more extensive disease. Thurlbeck also found an overlap in linear intercept values between macroscopically emphysematous and non-emphysematous lung. ${ }^{33}$ Duguid et al found that macroscopic lesions were associated with an almost $50 \%$ reduction in airspace surface area per unit volume. ${ }^{30}$ However, there were only four normal patients in their study, patients were not matched for age, and many of the abnormal cases were of patients with coal workers' pneumoconiosis as well as emphysema. Thus assessment of macroscopic emphysema does not necessarily parallel underlying airspace destruction. In our study this was true for the sample as a whole and also for the subgroups with mixed, panacinar, or pure centriacinar disease. In particular, although ranging as high as $79 \%$ by area, the severity of panacinar disease correlated poorly with the airspace wall surface area per unit volume.

There were some exceptions to the generally poor relation between macroscopic emphysema and airspace destruction. In patients with macroscopic centriacinar emphysema the number of discrete lesions counted macroscopically correlated with both mean airspace wall surface area per unit volume and the mean of five fields with the lowest values of surface area (although the area of macroscopic emphysema did not). These relations were impressive as macroscopic centriacinar emphysema never affected more than $5 \%$ of the mid-sagittal slice. This relation between the number of centriacinar lesions and airspace wall surface area per unit volume suggests that centriacinar lesions develop on a background of general parenchymal loss. In support of this there was a strong correlation between the number of centriacinar lesions and $\mathrm{KCO}$ in patients with centriacinar emphysema. These observations may explain why Hayhurst et al found that centriacinar lesions were associated with a reduction in lung density when compared with lungs showing no macroscopic emphysema. $^{34}$ It must be remembered, however, that centriacinar emphysema has to date always been measured macroscopically as it is not yet possible to quantify centriacinar emphysema microscopically. Relations between microscopic and macroscopic centriacinar emphysema remain to be established.

The results of this study suggest that emphysema can be measured accurately only by microscopic measurements. Decrease in lung density and carbon monoxide gas transfer do not relate to the severity of macroscopic emphysema but correlate strongly with airspace wall surface area per unit volume. ${ }^{29}$ More importantly the relations between airspace wall surface area per unit volume, lung density, and carbon monoxide gas transfer are constant irrespective of the presence, type, or severity of macroscopic emphysema. Some authors have suggested that the relations between carbon monoxide gas transfer and macroscopic emphysema assessed by panel grading and point counting is linear. ${ }^{10182935}$ However, when the data are available it is obvious that these relations are not truly linear..$^{29}{ }^{35}$ In particular, subjects with no macroscopic emphysema can have gas transfer function which does not differ from that of subjects with severe macroscopic emphysema.

The fields with the largest airspace size of those measured are represented by the mean of five fields with the lowest airspace wall surface area per unit volume. This may represent areas of acquired emphysema but in many cases the larger airspaces measured are the alveolar ducts. The stronger correlation between the mean value of the lowest five fields and $\mathrm{KcO}$ compared with mean airspace wall surface area per unit volume and Kco may reflect the importance of the proximal acinar airsyaces in this single breath technique for measuring gas transfer.

Our results indicate that macroscopic measurements of emphysema do not reflect the loss of airspace wall surface area per unit lung volume accurately. Considerable microscopic loss of surface area may precede the presence of macroscopic emphysema, so the incidence and severity of smoking related parenchymal damage must be higher than that reported by authors using macroscopic criteria alone. Moreover, since centriacinar emphysema seems to develop on a background of general loss of airspace wall this may explain the apparent relation between centriacinar lesions and Kco.

1 Reid L. Pathological findings and radiological changes in chronic bronchitis and emphysema. Br J Radiol 1959; 32:291-8.

2 CIBA Guest Symposium. Terminology, definitions and classification of chronic pulmonary emphysema. Thorax 1959;14:286-99.

3 American Thoracic Society. Chronic bronchitis, asthma and pulmonary emphysema. Am Rev Respir Dis 1962;85: 762-8.

4 Snider GL, Kleinerman J, Thurlbeck WM. The definition of emphysema. Report of a National Heart, Lung and Blood Institute, Division of Lung Diseases Workshop. Am Rev Institute, Division of Lung

5 Burrows B. An overview of obstructive lung disease. Med Clin North Am 1981;3:455-71.

6 Thurlbeck WM. The incidence of pulmonary emphysema. Am Rev Respir Dis 1962;87:206-15.

7 Bignon J, Khoury F, Andre J, Brouet J. Morphometric study on chronic obstructive broncho-pulmonary disease. Am Rev Respir Dis 1969;99:669-95.

8 Bignon J, Andre-Bougaran J, Brouet G. Parenchymal, bronchiolar and bronchial measurements in centrilobular emphysema. Thorax 1970;25:556-67.

9 Mitchell RS, Stanford RE, Johnson JM, Silvers GW, Dart G, George MS. The morphologic features of the bronchi, bronchioles and alveoli in chronic airway obstruction. A clinicopathological study. Am Rev Respir Dis 1976; 114:137-45.

10 Thurlbeck WM, Henderson JA, Fraser RG, Bates DV. Chronic obstructive lung disease. Medicine 1970;49: 81-145.

11 Dunnill MS. Quantitative observations on the anatomy of chronic non-specific lung disease. Med Thorac 1965; 22:262-74.

12 Deppier A, Bignon J, Lebeau A, Brouet G. Quantitative study of parenchyma and small conductive airways in

13 Cosio MG, Ghezzo H, Hogg JC, Corbin R, Loveland M, Dosman $J$, et al. The relations between structural changes in small airways and pulmonary function tests. $N$ Engl J Med 1977;298:1277-81. 
14 Cosio MG, Hale KA, Niewoehner DE. Morphological and morphometric affects of prolonged cigarette smoking on the small airways. Am Rev Respir Dis 1980;122:265-71.

15 Petty TL, Silver WG, Stanford RE. Functional correlations with mild and moderate emphysema in excised human lungs. Am Rev Respir Dis 1981;124:700-4.

16 Petty TL, Silver WG, Stanford WG. Small airways disease is associated with elastic recoil changes in excised human lungs. Am Rev Respir Dis 1984;130:42-5.

17 Berend N, Woolocock AJ, Martin GE. Correlation between the function and structure of the lung in smokers. Am Rev the function and structure of

18 Pare PD, Brooks LA, Bates J, Lawson LM, Nelems JMB, Wright $\mathrm{JL}$, et al. Experimental analysis of the lun pressure-volume curve as a predictor of pulmonary emphysema. Am Rev Respir Dis 1982;126:54-61.

19 Bergin C, Muller N, Nichols DM, Lillington G, Hogg JC Mullen B, et al. The diagnosis of emphysema. Am Rev Respir Dis 1986;133:541-6.

20 Ryder RC, Thurlbeck WM, Gough J. A study of interobserver variation in the assessment of the amount of pulmonary emphysema in paper mounted whole lung sections. Am Rev Respir Dis 1969;99:354-64.

21 Heard BE. The pathology of chronic bronchitis and emphysema. London: J and A Churchill, 1969.

22 Thurlbeck WM, Horowitz I, Siemiatychi J, Dunnill MS Maisel JC, Pratt P, et al. Intra- and inter-observer Maisel JC, Pratt P, et al. Intra- and inter-observer variations in the assessn

23 Dunnill MS. Quantitative methods in the study of pulmonary pathology. Thorax 1962;17:320-6.

24 Cambell IA, Tomkeieff SA. Calculation of internal surface area. Nature 1952;170:117.
25 Weibel ER. Morphometry of the human lung. Berlin: Springer Verlag, 1963.

26 McLean J Pathol 1983;141:520.

27 Williams MA. Quantitative methods in biology. In: Glauert AM, ed. Practical methods in electron microscopy. Amsterdam: North Holland, 1977.

28 Ogilvie CM, Forster RE, Blakemore WS, Morton JW. A standardised breath holding technique for the clinical measurement of the diffusing capacity of the lung for carbon monoxide. J Clin Invest 1957;36:1-17.

29 Gould GA MacNee W, McLean A, Warren P, Redpath A, Best JJK, et al. CT measurement of lung density can Buantitate distal airspace enlargement-an essential defining feature of human emphysema. Am Rev Respir Dis 1988;137:380-92.

30 Duguid JB, Young A, Cauna D, Lambert MW. The internal Duguid JB, Young A, Cauna D, Lambert MW. The internal
surface area of the lung in emphysema. Journal of Pathology and Bacteriology 1964;88:405-21.

31 Thurlbeck WM. The internal surface area of nonemphysematous lungs. Am Rev Respir Dis 1967;95: 765-73.

32 Angus GE, Thurlbeck WM. Number of alveoli in human lung. Applied Physiology 1972;32:483-5.

33 Thurlbeck WM. Internal surface area and other measurements in emphysema. Thorax 1967;22:483-96.

34 Hayhurst MD, MacNee W, Wright D, McLean A, Lamb D, Flenley DC. The diagnosis of pulmonary emphysema by CT scanning. Lancet 1984;ii:320-2.

35 Greaves IA Colebatch $\mathrm{HJH}$. Observations on the pathogenesis of chronic airflow obstruction in smokers: implicagenesis of chronic airfiow obstruction in smokers: implica1986;41:81-7. 